\title{
SARCOMA SINOVIAL DE EXTREMIDADES COM DOENÇA LOCALIZADA AO DIAGNÓSTICO: TRATAMENTO E PADRÕES DE RECIDIVA EM 57 CASOS
}

\author{
LOCALIZED EXTREMITY SINOVIAL SARCOMA: TREATMENT AND PATTERNS OF \\ RECURRENCE IN 57 CASES
}

\author{
Danton S. Corrêa, TCBC-SC ${ }^{1}$; Isabela W. da Cunha ${ }^{2}$; André L. Carvalho ${ }^{3}$; \\ Fernando A Soares ${ }^{4}$; Roberto Fauzoni ${ }^{5}$; Ademar Lopes, TCBC-SP
}

\begin{abstract}
RESUMO: Objetivos: Os sarcomas sinoviais são tumores raros e agressivos que acometem adultos jovens, com sobrevida doençaespecífica em cinco anos de 57 a $63 \%$. O presente estudo analisa a experiência institucional com este tumor, dando ênfase à associação entre variáveis clínicas, padrões de recorrência e sobrevida. Método: Entre 1970 e 2001 foram identificados 57 pacientes com sarcomas sinoviais. Fatores demográficos, clínicos e anatomopatológicos foram pesquisados. Associações entre variáveis clínicas e a sobrevida livre de recidiva local, livre de metástases e doença-específica em cinco anos foram calculadas. Resultados: A idade mediana dos pacientes foi 26 anos, $56 \%$ eram masculinos, $79 \%$ eram brancos. Localizavam-se em membro inferior em $74 \%$, proximalmente em $53 \%$. O sintoma mais comum foi a presença de tumor em $42 \%$. Na admissão $18 \%$ eram intactos, $42 \%$ manipulados e $40 \%$ recidivados. A maioria era maior que $5 \mathrm{~cm}$., e três pacientes apresentavam metástase linfonodal. A cirurgia mais freqüente foi ressecção ampla, 30\% necessitou amputação. Margens amplas foram obtidas em $65 \%, 51 \%$ eram tumores bifásicos. Neoadjuvância foi utilizada em $46 \%$ e adjuvância em $58 \%$ dos casos. As sobrevidas livre de recidiva local , metástases e doença específica em cinco anos foram $60 \pm 8 \%, 47 \pm 7 \%$ e $58 \pm 7 \%$. A localização proximal do tumor associou-se com preservação de membro $(\mathrm{p}=-0,001)$, margens inadequadas $(\mathrm{p}=0,006)$ e subtipo bifásico $(\mathrm{p}=0,047)$. Conclusões: Os dados confirmam a hipótese de tratar-se de tumor agressivo, com altos índices de recidiva local e à distância. Os resultados do tratamento são comparáveis a outros centros especializados. Tratamento fora destes centros deve ser desencorajado (Rev. Col. Bras. Cir. 2005; 32(6): 304-309).
\end{abstract}

Descritores: Sarcoma sinovial; Tratamento; Recidiva.

\section{INTRODUÇÃO}

Os sarcomas sinoviais são tumores raros, compreendendo aproximadamente 5 a $10 \%$ dos sarcomas de partes moles $^{1,2}$. São mais comuns em extremidades, embora possam originar-se em qualquer parte do corpo sem qualquer relação com membranas sinoviais ${ }^{2,3}$. Acometem principalmente adultos jovens e apresentam-se como uma massa dolorosa de crescimento lento próxima a uma grande articulação, especialmente a região do joelho ${ }^{3}$. Histologicamente podem ser de dois tipos, monofásico e bifásico, baseados na presença ou ausência de diferenciação glandular epitelial junto a células tumorais fusiformes ${ }^{3-6}$. Apresentam uma translocação característica entre o cromossomo 18 e o X, t(X;18)(p11; q11), presente em mais de $90 \%$ deles, o que pode auxiliar no diagnóstico em casos não característicos ${ }^{7,8}$. São tumores agressivos, recidivando localmente em torno de 12 a $31 \%$, mesmo com tratamento adequado, e à distância, entre 39 e $54 \%$ dos ca$\operatorname{sos}^{1,9,10}$. Metastatizam principalmente para pulmões ${ }^{11,12} \mathrm{e}, \mathrm{em}$ torno de 3-7\%, para linfonodos ${ }^{4,13-16}$. Apresentam índices de resposta à quimioterapia mais altos do que o restante dos sarcomas em adultos ${ }^{17-19} \mathrm{e}$ índices de sobrevida doença-espe- cífica em cinco anos de 57 a $63 \% \%^{1,15,16}$. O presente estudo visa a analisar a experiência do Hospital do Câncer AC Camargo com o tratamento de sarcomas sinoviais de extremidades e sem doença à distância no momento da admissão. Associações entre variáveis clínicas, os padrões de recorrência e sobrevida são enfatizados.

\section{MÉTODO}

Os registros anatomopatológicos de pacientes operados no Hospital do Câncer AC Camargo entre janeiro de 1970 e dezembro de 2001 foram pesquisados e destes selecionados os com diagnóstico de sarcoma sinovial. A partir destes registros, prontuários foram recuperados do serviço de arquivo médico do hospital e revisados, sendo escolhidos para análise os correspondentes a tumores de extremidades. Após esta primeira seleção foi realizada revisão de lâminas para confirmação diagnóstica por três patologistas. O diagnóstico dos tumores bifásicos foi realizado através de padrão histológico característico, enquanto os monofásicos tiveram confirmação através da expressão imuno-histoquímica de EMA (Figura 1). De um grupo inicial de 89 casos, não foi possível a

1. Médico, Departamento de Cirurgia Pélvica, Hospital do Câncer AC Camargo

2. Médica, Departamento de Anatomia Patológica, Hospital do Câncer AC Camargo.

3. Médico, Departamento de Cirurgia de Cabeça e Pescoço, Hospital do Câncer AC Camargo.

4. Diretor, Departamento de Anatomia Patológica, Hospital do Câncer A.C.Camargo.

5. Médico consultor, Departamento de Anatomia Patológica, Hospital do Câncer AC Camargo.

6. Diretor, Departamento de Cirurgia Pélvica, Hospital do Câncer AC Camargo

Recebido em 01/07/2005

Aceito para publicação em 11/10/2005

Conflito de interesse : nenhum

Fonte de financiamento : FAPESP

Trabalho realizado no Departamento de Cirurgia Pélvica do Hospital do Câncer AC Camargo da Fundação Antônio Prudente - São Paulo. 

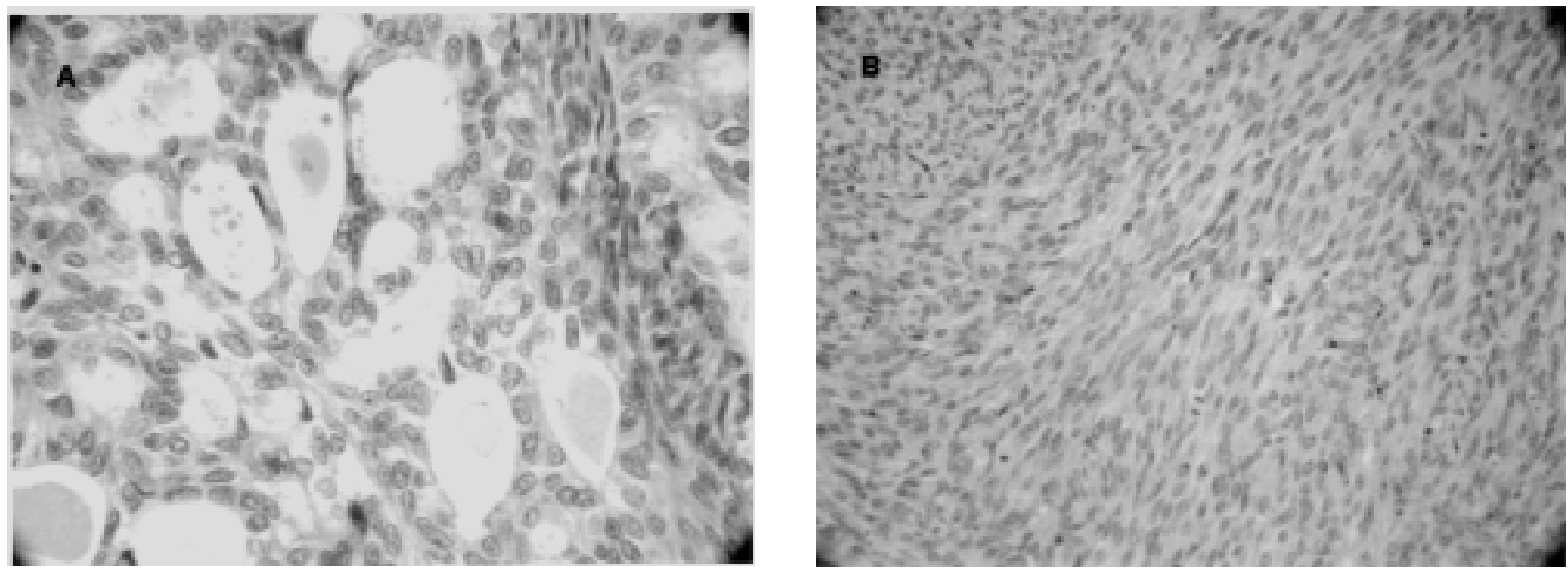

Figura 1 - Sarcoma sinovial - subtipos histológicos: A- bifásico, B-monofásico.

confirmação do diagnóstico inicial em 17 e em oito casos a quantidade de material disponível não era adequada para nova análise. Dos 64 casos remanescentes, sete apresentavam doença metastática no momento da admissão, sendo também excluídos do estudo. A análise foi realizada, portanto, nos 57 casos de pacientes com sarcomas sinoviais de extremidades com doença localizada ao diagnóstico. As variáveis pesquisadas foram: sexo, idade, raça, localização na extremidade, sintomas e duração, situação na admissão (intacto, manipulado ou recidivado), tamanho do tumor (estadio T), comprometimento linfonodal (estadio $\mathrm{N}$ ), número de recidivas prévias, avaliação de ressecabilidade, tipo de ressecção (amputação ou preservação de membro), tipo de reparo, transfusão de sangue, margem cirúrgica, complicações, uso ou não de neoadjuvância ou adjuvância, subtipo histológico, ocorrência de recidivas locais e à distância incluindo forma de tratamento das mesmas e tempo mediano para sua ocorrência e óbito pela doença. Associações entre variáveis clínicas relacionadas a características tumorais e de tratamento foram estabelecidas através de teste exato de Fisher ou Qui-Quadrado de Pearson, na dependência do número esperado de ocorrências de uma variável ser $>$ ou $<5$. O nível de significância considerado foi de erro tipo I (alfa) igual ou menor que 0,05 . A sobrevida livre de recidiva local, sobrevida livre de metástases e sobrevida doença-específica em cinco anos foram calculadas utilizando o método de Kaplan-Meier. Todos os tumores foram considerados de alto grau, por definição ${ }^{20}$.

\section{RESULTADOS}

Para os 57 pacientes avaliados, a idade variou de quatro a 73 anos, com mediana de 26 e média de 30,12. Destes, oito (14\%) tinham até 16 anos, 36 (63\%) entre 17 e 40 anos e $13(23 \%)$ com mais de 40 anos. Com relação ao sexo, 32 pacientes eram do sexo masculino (56\%) e 25 do sexo feminino (44\%). Quanto à raça, 45 pacientes eram brancos $(79 \%)$ e 12 nãobrancos $(21 \%)$. Os dados demográficos encontram-se sumarizados na Tabela 1.

Levando-se em conta a localização, cinco pacientes apresentavam tumor na região proximal do membro superior
(9\%); nove na região distal do membro superior (16\%); 25 na região proximal do membro inferior (44\%); e 18 na região distal do membro inferior (30\%).

O sintoma mais comum foi a presença isolada de tumor, em 24 pacientes (42\%). A presença de dor associada ao tumor ocorreu em 21 pacientes (37\%). A associação de dor e tumor a parestesia ocorreu em seis casos (11\%), e destes dois com impotência funcional (4\%). A presença de dor e tumor associados à ulceração ocorreu em dois casos (4\%) e a de dor isoladamente em um caso (2\%). A associação do tumor a trauma local foi referida espontaneamente por oito pacientes (14\%). A duração dos sintomas foi avaliada somente em pacientes intactos ou com biópsias prévias (22 pacientes) e variou de dois a 144 meses, com média de 19,59 meses e mediana de oito meses.

No momento da admissão, com relação a manipulação prévia do tumor $10(18 \%)$ eram intactos, 24 manipulados (42\%) e 23 recidivados (40\%).

Com relação ao estadio T, sete tumores (12\%) tinham tamanho menor ou igual a $5 \mathrm{~cm}$ (T1), 25 tumores (44\%) eram maiores que $5 \mathrm{~cm}$ (T2) e 25 (44\%) tumores tinham o tamanho não avaliável (Tx). Entre os tumores T2, 13 (23\%) eram maiores que $10 \mathrm{~cm}$. Para o estádio $\mathrm{N}$, três pacientes $(5 \%)$ apresentavam metástase linfonodal ao diagnóstico.

De acordo com a avaliação clínica quanto a ressecabilidade, 10 pacientes tiveram indicação de amputação desde a primeira avaliação (18\%), 19 pacientes foram avaliados como tendo ressecabilidade duvidosa (33\%) e 28 pacien-

Tabela 1 - Sarcoma sinovial - dados demográficos.

\begin{tabular}{llrl}
\hline Variável & Categoria & $\mathbf{n}$ & $\mathbf{\%}$ \\
\hline sexo & masculino & 32 & 56 \\
& feminino & 25 & 44 \\
idade & até 16 anos & 8 & 14 \\
& $17-40$ anos & 36 & 63 \\
& $>40$ anos & 13 & 23 \\
raça & brancos & 45 & 79 \\
& não-brancos & 12 & 21 \\
\hline
\end{tabular}


Tabela 2 - Sarcoma sinovial - dados referentes ao tumor.

\begin{tabular}{llrc}
\hline Variável & Categoria & n & \% \\
\hline local no membro & MS proximal & 5 & 9 \\
& MS distal & 9 & 16 \\
& MI proximal & 25 & 44 \\
\multirow{4}{*}{ sintomas } & MI distal & 17 & 30 \\
& tumor & 24 & 42 \\
& tumor +dor & 21 & 37 \\
status local & outros & 12 & 21 \\
& intacto & 10 & 18 \\
& manipulado & 24 & 42 \\
categoria T & recidivado & 23 & 40 \\
& TX & 25 & 44,8 \\
& T1 & 7 & 12,0 \\
categoria N & T2 & 25 & 43,2 \\
& N0 & 54 & 95 \\
subtipo & N1 & 3 & 5 \\
histológico & monofásico & 29 & 51 \\
\hline
\end{tabular}

tes como sendo ressecáveis sem amputação (49\%). Todos os pacientes com ressecabilidade duvidosa foram submetidos a neoadjuvância, além de sete outros pacientes com grandes tumores (45\%). Destes 26, quatro receberam quimioterapia isolada (15\%), 13 quimioterapia associada a radioterapia $(50 \%) \mathrm{e}$ nove radioterapia isolada (35\%). Após tratamento neoadjuvante, a amputação foi necessária em sete casos (37\%); foi possível a preservação do membro em 12 pacientes (63\%). No total, a ressecção ampla foi a cirurgia mais utilizada, possível em 40 pacientes . O reparo da ferida operatória foi primário em 50 casos $(88 \%)$, em seis casos foi necessária a rotação de retalhos (10\%) e em um caso enxerto livre de pele $(2 \%)$.

Com relação à necessidade de transfusão, esta foi necessária em 10 casos (18\%) enquanto 47 pacientes não receberam sangue $(82 \%)$.

As margens foram consideradas adequadas (microscopicamente livres) em 37 (65\%) pacientes, exíguas (tumor em íntimo contato com feixe neurovascular ou estrutura óssea, mesmo com margens microscópicamente livres) em 13 (23\%) pacientes, inadequadas (margem microscópica comprometida) em três (5\%) pacientes e não avaliáveis em quatro pacientes $(7 \%)$.

Quanto ao subtipo histológico, 29 pacientes tiveram o diagnóstico de sarcomas sinoviais bifásicos (51\%) e 28 monofásicos (49\%).

Complicações de ferida operatória aconteceram em 13 pacientes $(23 \%)$. Destes pacientes, oito receberam alguma forma de neoadjuvância (62\%).

Com relação a terapia adjuvante, 24 pacientes $(43 \%)$ não realizaram nenhuma forma de terapia, enquanto 33 receberam alguma forma de tratamento $(57 \%)$. Destes, 15 pacientes receberam apenas radioterapia $(45 \%)$, nove pacientes receberam quimio e radioterapia $(27 \%)$ e nove pacientes apenas quimioterapia (27\%). Dos 33, 20 não haviam recebido nenhuma forma de neoadjuvância. Os dados referentes às caracte-
Tabela 3 - Sarcoma sinovial - dados referentes ao tratamento.

\begin{tabular}{llcr}
\hline Variável & Categoria & n & \% \\
\hline neoadjuvância & sim & 26 & 46 \\
& não & 31 & 54 \\
tipo de cirurgia & preservação de & & \\
& membro & 40 & 70 \\
& amputação & 17 & 30 \\
transfusão & sim & 10 & 18 \\
margem & não & 47 & 82 \\
& adequada & 37 & 65 \\
& exígua & 13 & 23 \\
& inadequada & 3 & 5 \\
complicações de & não avaliável & 4 & 7 \\
ferida operatória & sim & & \\
& não & 13 & 23 \\
adjuvância & sim & 44 & 77 \\
& não & 33 & 58 \\
& & 24 & 42 \\
& & & \\
\hline
\end{tabular}

rísticas tumorais e tratamento encontram-se sumarizados nas Tabelas 2 e 3

A recidiva local após admissão no Hospital do Câncer AC Camargo aconteceu em 17 pacientes (30\%). O tempo mediano até a primeira recidiva foi de 27 meses. O tratamento da recidiva local foi exclusivamente cirúrgico em 10 casos $(59 \%)$, cirurgia associada a radioterapia em quatro casos $(23 \%)$ , quimioterapia associada radioterapia em um caso $(6 \%) \mathrm{e}$ quimioterapia exclusiva em um caso (6\%). A amputação ou desarticulação foi indicada como tratamento cirúrgico da recidiva em nove casos $(53 \%)$ e foi realizada em oito pacientes $(47 \%)$, um recusou o procedimento. O caso em que foi administrada apenas quimioterapia tratava-se de uma recidiva em coto de amputação associado a metástases pulmonares.

Metástases à distância ocorreram em 33 pacientes (58\%). O tempo mediano até a primeira metástase foi de 15,9 meses. Os sítios de metástase mais frequientes foram pulmões $(85 \%)$ e ossos $(24 \%)$. Em 19 pacientes, as metástases eram exclusivamente pulmonares $(55,8 \%)$. Nestes, 11 foram submetidos a ressecção cirúrgica das mesmas, sete associados a quimioterapia (combinações a base de adriamicina). No restante, quimioterapia exclusiva ou combinada com radioterapia foi administrada. Em três pacientes nenhum tratamento foi realizado.

Os dados referentes ao resultado do tratamento encontram-se sumarizados na Tabela 4.

Tabela 4 - Sarcoma sinovial - dados relacionados ao resultado do tratamento.

\begin{tabular}{llll}
\hline Variável & Categoria & n & \% \\
\hline recidiva local & sim & 17 & 30 \\
\multirow{2}{*}{ metástases } & não & 40 & 70 \\
\multirow{3}{*}{ óbito por tumor } & sim & 33 & 58 \\
& não & 24 & 42 \\
& sim & 29 & 51 \\
& não & 28 & 49 \\
\hline
\end{tabular}


Em relação a associação entre as variáveis clínicas estudadas, não houve associação significativa envolvendo status local, tamanho do tumor, status linfonodal e uso de terapia adjuvante. A localização proximal do tumor associouse com preservação de membro $(\mathrm{p}=-0,001)$, margens inadequadas $(\mathrm{p}=0,006)$ e subtipo bifásico $(\mathrm{p}=0,047)$. Os tumores distais associaram-se com amputação $(\mathrm{p}=-0,001)$, margens adequadas $(\mathrm{p}=0,006)$ e subtipo monofásico $(\mathrm{p}=0,047)$. O uso de neoadjuvância associou-se com margens adequadas $(\mathrm{p}=0,02)$, necessidade de transfusão $(\mathrm{p}=0,032)$ e subtipo bifásico $(\mathrm{p}=0,035)$.

As sobrevidas livre de recidiva local, livre de metástases e doença específica em cinco anos foram, respectivamente, $60 \pm 8 \% ; 47 \pm 7 \% ; 58 \pm 7 \%$. O tempo mediano de seguimento foi de 36 meses.

\section{DISCUSSÃO}

O objetivo deste estudo foi o de relatar uma série histórica de pacientes com sarcomas sinoviais de extremidades, com ênfase na descrição de variáveis clínicas e suas interações, padrões de recorrência e sobrevida.

A idade mediana da população em estudo foi 26 , confirmando ser este um tumor de adultos jovens ${ }^{3,15,16,21}$. Houve uma leve predileção pelo sexo masculino nesta casuística, coincidente com descrições clássicas ${ }^{3}$. Tentativas de associação da idade ou sexo do paciente com prognóstico são conflitantes. Parece haver uma tendência a melhor prognóstico em paciente jovens ${ }^{1,10-12}(<20-25$ anos) e do sexo feminino ${ }^{16,22}$, mas este dado não se confirmou em análises multivariadas de um estudo com casuística mais consistente ${ }^{9}$.

O sarcoma sinovial tem sido descrito como mais freqüente próximo a grandes articulações, principalmente joe1 ho ${ }^{3}$. A localização mais freqüente em nosso estudo foi a proximal do membro inferior $(43,2 \%)$, sendo que de 25 tumores 23 eram em coxa e apenas dois em proximidade ao joelho. Levando-se em conta que o conceito de que o sarcoma sinovial se origina de tecido sinovial articular é errôneo ${ }^{23}$, este resultado não surpreende. Alguns estudos fazem menção de que tumores proximais teriam tendência a serem maiores e de maior dificuldade para obtenção de margens livres ${ }^{24,25}$. Em nossa casuística, tumores proximais tiveram associação significativa com margem inadequada, enfatizando este aspecto.

A presença isolada de tumor e de tumor associado a dor foram os sintomas mais comuns e são coincidentes com referências prévias ${ }^{1,3,11,21,26}$. O tempo mediano entre o aparecimento de sintomas e a apresentação foi de oito meses, o que reflete o crescimento lento do tumor apesar de o mesmo ser de alto grau. O período mais longo nesta série foi de 144 meses. Este período é variável na literatura e existem relatos de intervalos tão longos quanto vários anos após o início de sintomas $^{3}$. A relação com trauma foi referida por oito pacientes $(13,7 \%)$. Outros estudos já tentaram mostrar esta correlação sem sucesso ${ }^{3,6,27}$. Aparentemente o trauma só chama a atenção para um tumor já existente no local.

A maior parte dos tumores nesta série já haviam sofrido manipulação prévia e ou já eram recidivados. Isto parece ser um fator de mau prognóstico ${ }^{1,6}$, embora alguns autores discordem desta opinião ${ }^{28,29}$. O fato é que incisões de biópsia mal posicionadas, tentativas de exérese sem diagnóstico prévio com margens inadequadas, violação de planos anatômicos entre outras falhas de técnica, se não pioram o prognóstico, com certeza dificultam o trabalho do cirurgião que recebe o caso em um centro de referência.

O tamanho do tumor parece ser o fator prognóstico mais consistente na maior parte das séries ${ }^{1,5,6,9-12}$. Tumores maiores que $5 \mathrm{~cm}$ possuem pior prognóstico, e permanecem como variável independente de prognóstico após análise multivariada. Nesta casuística a maior parte dos tumores avaliáveis eram maiores que $5 \mathrm{~cm}$. Isso é condizente com o período longo entre o início de sintomas e a apresentação. Apesar disso, a sobrevida doença-específica é comparável a de séries com menores tumores ${ }^{1,15}$. A presença de linfonodos comprometidos ao diagnóstico em sarcomas sinoviais ocorre entre 3 a $7 \%{ }^{4,13-17}$ e estava presente nesta série em três pacientes. Destes, dois vieram a falecer após dois e nove anos de seguimento.

A simples ressecção de sarcomas de partes moles resultou no passado em índices inaceitáveis de recidiva, tão altos quanto $65 \%{ }^{30}$. Nas últimas duas décadas, avanços no uso de terapia multimodal resultou em índices de controle local de $95 \%$ e amputações em menos de $10 \%$ dos $\operatorname{casos}^{31}$, sem prejuízo em sobrevida ${ }^{9,13}$. Neste estudo 17 (29,3\%) pacientes foram submetidos a amputação, sete deles após tentativa de redução do tumor com neoadjuvância. Isso reflete a alta incidência de tumores T2 volumosos em nossa casuística, além da inclusão de casos pré-era de tratamento multimodal. Em contrapartida, a preservação foi possível em 12 pacientes que no passado teriam sido amputados. A maior parte dos pacientes não necessitou transfusão sangüínea embora tenha havido uma associação significativa entre uso de neoadjuvância e uso de hemoderivados. Isso possivelmente se deve a alterações locais de vascularização e fibrose dificultando dissecção adequada. Outro fator de mau prognóstico consistente na literatura é a presença de margem microscópica comprometi$\mathrm{da}^{5,16}$. Este fator, como o tamanho tumoral, permanece significativo mesmo após análise multivariada nestas séries. A proximidade a estas estruturas não é incomum: 16 de nossos pacientes estavam nesta situação, três dos quais não foi possível a obtenção de margem livre. Dos 13 com margem exígua quatro recidivaram e dos três com margem comprometida dois tiveram recidivas locais. Isto corrobora a importância da margem no controle local da doença mesmo com o uso de tratamento multimodal. Em nosso estudo, houve uma associação significativa entre margem adequada e o uso de neoadjuvância.

O subtipo histológico tem sido amplamente avaliado como fator prognóstico na literatura. Embora existam descrições de que o tipo monofásico seria mais agressivo ${ }^{1,17}$, outros discordam deste fato e não vê diferença entre eles ${ }^{10,24}$. Em nossa casuística, cada subtipo representa metade da série. O número de recidivas locais e à distância encontrava-se igualmente distribuído entre os subtipos. Houve uma associação significativa entre o subtipo e o local no membro, tumores bifásicos possuindo localização predominantemente proximal e monofásicos distal. O subtipo monofásico também associou-se a maior índice de amputação. 
As complicações de ferida operatória aconteceram em $22,4 \%$ dos pacientes. Destes, $61,5 \%$ receberam alguma forma de neoadjuvância. Complicações de ferida são mais freqüentes em pacientes recebendo radioterapia pré-operatória. O' Sullivan ${ }^{32}$ descreve uma freqüência de $35 \%$ de complicações locais quando utilizada radioterapia pré-operatória comparado com $17 \%$ quando a radioterapia é pós-operatória. Eilber $^{33}$ descreve um índice de complicação local de $26 \%$ com o uso de quimioterapia e radioterapia associadas no período pré-operatório. Nosso índice de complicações é compatível com tais estudos.

A terapia adjuvante foi utilizada em $56,9 \%$ dos pacientes. Embora a radioterapia pós operatória tenha um papel bem definido no controle local da doença ${ }^{34}$ e a quimioterapia neoadjuvante venha ganhando mais adeptos ${ }^{33,35}$, o uso da quimioterapia adjuvante é mais controverso. Vários estudos não conseguiram mostrar benefício em seu uso,9,12,16,24,25, mas aparentemente quando utilizada em um subgrupo de pacientes com tumores maiores do que $5 \mathrm{~cm}$ e em pacientes com mais de 20 anos pode haver ganho de sobrevida ${ }^{1}$. Nosso critério de seleção para o uso de quimioterapia foi variável, dependendo do protocolo institucional da época, não possibilitando nenhuma forma de análise.

O impacto da recidiva local na sobrevida em sarcomas de extremidades permanece incerto. Alguns autores indicam a recidiva como um grave fator prognóstico ${ }^{6,12}$, outros não concordam ${ }^{28,29}$. Evans ${ }^{28}$ destaca a diferença entre persistência de doença e recidiva local verdadeira, a primeira sendo um evento inocente quando tratada com nova ressecção adequada. A recidiva local aconteceu em $27,6 \%$ dos pacientes de nossa série e a sobrevida livre de recidiva local em cinco anos foi de $62,28 \%$. O resgate cirúrgico foi possível em $87,5 \%, 56,2 \%$ dos quais com amputação. Stojadinovic ${ }^{36}$ descreve em uma série de 1178 pacientes com vários tipos histológicos de sarcomas um índice de recidiva local de 17\%, 9\% necessitando amputação para resgate, índices bem mais baixos que os nossos. No entanto, esta série não incluiu tumores de dígitos, pés e mãos e pacientes que já se apresentavam como recidiva. Concluindo, concordamos com $\mathrm{Ueda}^{29}$ que a recidiva representa um marcador de agressividade, mas que raramente é o responsável pelo óbito do paciente.

Metástases à distância aconteceram em $58,6 \%$ e a sobrevida livre de metástases em cinco anos foi de $46,56 \%$. Em mais da metade as metástases foram exclusivamente pulmonares, $57,8 \%$ sendo submetidos a metastasectomia cirúrgica. Outros estudos mostram índices de metástases à distância entre 40 e $50 \%{ }^{9}$, principalmente para pulmões ${ }^{6,11,16}$, tendo como fatores preditivos o tamanho do tumor (T2) e invasão de estrutura óssea ou neurovascular ${ }^{9,12}$. A maioria de nossos pacientes eram T2 e os com invasão óssea ou neurovascular fizeram parte do grupo amputados. Dos pacientes T2, 45\% apresentaram metástases, assim como dois dos três pacientes do grupo T1. Dos amputados, $65 \%$ apresentaram metástases. Embora existam evidências de que os sarcomas sinoviais tenham melhor resposta à quimioterapia que outros tipos histológicos ${ }^{19}$, sobrevida a longo termo em pacientes com estádio IV só é possível em casos selecionados de ressecção completa de metástases pulmonares exclusivas $^{37}$. Apenas um de nossos 11 pacientes com ressecção pulmonar de metástases permanece livre sem doença.

A presente série reflete uma experiência de mais de 30 anos no tratamento desta doença em nossa instituição, com todos os casos incluídos preenchendo critérios atuais de diagnóstico de sarcoma sinovial. A sobrevida doença-específica em cinco anos atingida foi de 56,78\%. Este índice é comparável aos obtidos atualmente em centros de referência para tratamento de $\operatorname{sarcomas}^{1,15,16}$, que infelizmente não tem melhorado. Apesar de existirem séries com melhores resultados ${ }^{9}$, isto ocorreu pela inclusão apenas de pacientes intactos e com tumores menores. Ainda assim é importante ressaltar a necessidade de tratamento em centros especializados e dedicados ao tratamento desta rara doença, para que melhores resultados possam ser obtidos.

\begin{abstract}
Background: Synovial sarcoma is a rare and aggressive tumor more frequently affecting young adults and has a 5 year disease specific survival of 57-63\%. The present study describes the institutional experience with the treatment of this tumor, emphasizing associations between clinical variables, patterns of recurrence and survival. Methods: Between 1970 and 2001, 57 patients were identified with synovial sarcomas. Demographic, clinical and histological factors were analyzed. Associations between clinical variables and 5 year local recurrence free, metastasis free and disease specific survival were calculated. Results: Median patient age was 26 years, $56 \%$ were male and $79 \%$ caucasians. Tumors were located in the lower limb in 74\%, proximally in 53\%. The most common symptom was the presence of tumor in $42 \%$. At admission, $18 \%$ were intact, $42 \%$ manipulated and $40 \%$ recurrent. Most of them were larger than $5 \mathrm{~cm}, 3$ patients had lymph node metastasis. The most common procedure was extensive resection, $30 \%$ were amputated. Wide margins were obtained in $65 \%$, 51\% were biphasic tumors. Neoadjuvant therapy was performed in 46\%, 56\% had adjuvant therapy. The 5 year local recurrence free, metastasis free and disease specific survival were $60 \pm 8 \%, 47 \pm 7 \%$ e $58 \pm 7 \%$. Proximal location was associated with limb sparing procedures $(p=0.001)$, close margins $(p=0.006)$ and biphasic tumors $(p=0.047)$.Conclusion: Data support the hypothesis that this is an aggressive tumor, with high rates of local and remote recurrences. The survival obtained was comparable to other reference centers. Treatment outside these centers should be discouraged.
\end{abstract}




\section{REFERÊNCIAS}

1- Bergh P, Meis-Kindblom JM, Gherlinzoni F, et al. Synovial sarcoma: identification of low and high risk groups. Cancer.1999; 85(12):2596-607.

2- Cadman NL, Soule EH, Kelly PJ- Synovial sarcoma: an analysis of 34 tumors. Cancer.1965;18:613-27.

3- Weiss SW, Goldblum JR. Enzinger and Weiss's soft tissue tumours. $4^{\text {a }}$ ed. St. Louis: Mosby; 2001.

4- Brodsky JT, Burt ME, Hajdu SI, et al. Tendosynovial sarcoma. Clinicopathologic features, treatment, and prognosis. Cancer.1992;70(2):484-9.

5- Singer S, Baldini EH, Demetri GD, et al. Synovial sarcoma: prognostic significance of tumor size, margin of resection, and mitotic activity for survival. J Clin Oncol.1996;14(4):1201-8.

6- Deshmukh R, Mankin HJ, Singer S. Synovial sarcoma: the importance of size and location for survival. Clin Orthop. 2004; (419):155-61.

7- Sreekantaiah C, Ladanyi M, Rodriguez E, et al. Chromosomal aberrations in soft tissue tumors. Relevance to diagnosis, classification, and molecular mechanisms. Am J Pathol.1994;144(6):1121-34.

8- Kawai A, Woodruff J, Healey JH, et al. SYT-SSX gene fusion as a determinant of morphology and prognosis in synovial sarcoma. N Engl J Med. 1998;338(3):153-60.

9- Lewis JJ, Antonescu CR, Leung DH, et al. Synovial sarcoma: a multivariate analysis of prognostic factors in 112 patients with primary localized tumors of the extremity. J Clin Oncol. 2000;18(10):2087-94.

10- Mullen JR, Zagars GK. Synovial sarcoma outcome following conservation surgery and radiotherapy. Radiother Oncol. 1994; 33(1):23-30.

11-Paulino AC. Synovial sarcoma prognostic factors and patterns of failure. Am J Clin Oncol. 2004; 27(2):122-7.

12- de Silva MV, McMahon AD, Reid R. Prognostic factors associated with local recurrence, metastases, and tumor-related death in patients with synovial sarcoma. Am J Clin Oncol. 2004;27(2):113-21.

13- Behranwala KA, A'Hern R, Omar AM, et al. Prognosis of lymph node metastasis in soft tissue sarcoma. Ann Surg Oncol. 2004; 11(7):714-9

14- Riad S, Griffin AM, Liberman B, et al. Lymph node metastasis in soft tissue sarcoma in an extremity. Clin Orthop. 2004;(426):129-34.

15- Spillane AJ, A'Hern R, Judson IR, et al. Synovial sarcoma: a clinicopathologic, staging, and prognostic assessment. J Clin Oncol. 2000;18(22):3794-803.

16- Trassard M, Le Doussal V, Hacene K, et al. Prognostic factors in localized primary synovial sarcoma: a multicenter study of 128 adult patients. J Clin Oncol. 2001;19(2):525-34.

17- Van Glabbeke M, van Oosterom AT, Oosterhuis JW, et al. Prognostic factors for the outcome of chemotherapy in advanced soft tissue sarcoma: an analysis of 2,185 patients treated with anthracycline containing first-line regimens-a European Organization for Research and Treatment of Cancer Soft Tissue and Bone Sarcoma Group Study. J Clin Oncol.1999;17(1):150-7.

18- Kampe CE, Rosen G, Eilber F, et al. Synovial sarcoma. A study of intensive chemotherapy in 14 patients with localized disease. Cancer. 1993;72(7):2161-9.

19- Rosen G, Forscher C, Lowenbraun S, et al. Synovial sarcoma. Uniform response of metastases to high-dose ifosfamide. Cancer, 1994,73(10):2506-11.
20- Fisher C. Synovial Sarcoma. Ann Diagn Pathol. 1998;2(6):401-21. 21- Pack GT, Ariel IM. Synovial sarcoma (malignant synovioma): a report of 60 cases. Surgery. 1950; 28(6):1047-084.

22- Wright PH, Sim FH, Soule EH, et al. Synovial sarcoma. J Bone Joint Surg Am.1982;64(1):112-22.

23- Haagenson CD, Stout AP- Synovial sarcoma. Ann Surg. 1944;120:826-42.

24- Oda Y, Hashimoto H, Tsuneyoshi M, et al. Survival in synovial sarcoma. A multivariate study of prognostic factors with special emphasis on the comparison between early death and long-term survival. Am J Surg Pathol. 1993;17(1):35-44.

25- Moberger G, Nilsonne U, Friberg S. Synovial sarcoma. Acta Orthop Scand.1968;(Suppl 111):3-38.

26- Meis-Kindblom JM, Enzinger FM. Color atlas of soft tissue tumors. St. Louis: Mosby-Wolfe; 1996 pp 189-200.

27- Scully SP, Temple HT, Harrelson JM. Synovial sarcoma of the foot and ankle. Clin Orthop. 1999;(364):220-6. 28- Evans RA. Soft tissue sarcoma: the enigma of local recurrence. J Surg Oncol.1993;53(2):88-91.

29- Ueda T, Yoshikawa H, Mori S, et al. Influence of local recurrence on the prognosis of soft-tissue sarcomas. J Bone Joint Surg Br. 1997;79(4):553-7.

30- Abbas JS, Holyoke ED, Moore R, et al. The surgical treatment and outcome of soft-tissue sarcoma. Arch Surg. 1981;116(6):765-9.

31- Karakousis CP, Proimakis C, Walsh DL. Primary soft tissue sarcoma of the extremities in adults. Br J Surg. 1995;82(9):1208-12.

32- O'Sullivan B, Davis A, Bell R, et al. Phase III randomized trial of preoperative versus post-operative radiotherapy in the curative management of extremity soft tissue sarcoma. ACanadian Sarcoma Group and NCI Canada Clinical Trials Group study. Proc ASCO. 1999;18:535a.

33- Eilber FR, Giuliano AE, Huth JH, et al. Neoadjuvant chemotherapy, radiation, and limited surgery for high grade soft tissue sarcoma of the extremity. In: Ryan JR, Baker LO, editors. Recent concepts in sarcoma treatment. Dordrecht: Kluwer Academic Publishers; 1988. p. 115-22.

34- Habrand JL, Le Pechoux C. Radiation therapy in the management of adult soft tissue sarcomas. Ann Oncol. 2004;15(Suppl 4):18791.

35- Henshaw RM, Priebat DA, Perry DJ, et al. Survival after induction chemotherapy and surgical resection for high-grade soft tissue sarcoma. Is radiation necessary? Ann Surg Oncol. 2001;8(6):48495.

36- Stojadinovic A, Jaques DP, Leung DH, et al. Amputation for recurrent soft tissue sarcoma of the extremity:indications and outcome. Ann Surg Oncol. 2001;8(6):509-18.

37- Billingsley KG, Burt ME, Jara E, et al. Pulmonary metastases from soft tissue sarcoma: analysis of patterns of diseases and postmetastasis survival. Ann Surg. 1999; 229(5):602-10; discussion 610-2.

Endereço para correspondência:

Ademar Lopes, TCBC

Hospital do Câncer A.C. Camargo

Departamento de Cirurgia Pélvica

Rua Prof. Antônio Prudente, 211

Liberdade

01509-900 -São Paulo - SP

E-mail: lopesa@uol.com.br 